\title{
Identificación Inicial de las Formas de Argumentación sobre Ecología en Escuela Rural
}

${ }^{1}$ Institución Educativa Juan de Jesús Acevedo

alexander.vargas02@uptc.edu.co

2.3. Universidad Pedagógica y

Tecnológica de Colombia

Como citar: Vargas, A., Torres, N., \& Ochoa, E. (2021). Identificación Inicial de las Formas de Argumentación sobre Ecología en Escuela Rural. EDUCACIÓN Y CIENCIA, (25), e11658. https:// doi.org/10.19053/0120-7105. eyc.2021.25.e11658

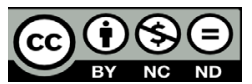

\section{Resumen}

El artículo tiene como objetivo mostrar los resultados de las formas de argumentación en ecología desarrolladas por estudiantes de contexto rural de octavo y noveno grado, sobre bosque andino y páramo haciendo abordajes de Cuestiones Socio Científicas. El estudio usó metodología cualitativa y se enmarcó en el paradigma hermenéutico interpretativo. Para el desarrollo, se aplicó un test diseñado por los autores para abordar el tema plateado. El análisis se enfoca en las categorías de contenido, estructura y discusión del argumento. Los resultados señalan que los estudiantes presentan dificultades en la construcción de argumentos, pues relacionan incorrectamente códigos científicos y las justificaciones o conclusiones carecen de coherencia y fundamentación para dar respuesta a cuestionamientos planteados. Se concluyó que la matriz de evaluación utilizada, los contenidos abordados y el análisis hecho, aportan a la comprensión sobre las formas de argumentación usadas por los estudiantes participantes.

Palabras clave: Argumentación, cuestiones sociocientíficas, escuela rural, aprendizaje

Recibido: 31/08/2020 ｜ Revisado: 16/09/2020

Aprobado: 15/03/2021 | Publicado: 16/05/2021 


\title{
Initial Identification of Forms of Argumentation about Ecology in School Rural
}

\begin{abstract}
The article aims to show the results of the forms of argumentation in ecology developed by students in the rural context of eighth and ninth grade, on Andean forest and Paramo making approaches of Socioscientific Issues. The study used qualitative methodology and was based on the interpretative hermeneutic paradigm. For the development, a test designed by the authors was applied to attend to the issue proposed. The analysis focuses on the categories of content, structure, and discussion of the argument. The results indicate that students present difficulties in the construction of arguments since they incorrectly relate scientific codes and the justifications or conclusions lack coherence and substantiation to answer questions presented. It was concluded that the evaluation matrix used, the contents addressed and the analysis made, contribute to the understanding of the forms of argumentation used by the participating students.
\end{abstract}

Keywords: Argumentation, socio-scientific questions, rural school, learning

\section{Introducción}

Se presenta aquí el estudio diagnóstico de la investigación: desarrollo de la argumentación en ecología en estudiantes de básica secundaria en escuela nueva, realizado en una institución educativa rural. Dicho estudio pretende contribuir al fortalecimiento de procesos de argumentación en la enseñanza de las ciencias naturales, específicamente en el área de ecología, abordando contenidos sobre bosque andino y páramo que aporten al pensamiento crítico y científico del estudiantado.

La argumentación como habilidad cognitiva pretende la construcción del pensamiento crítico y científico, por ello, guarda relación con la filosofía y su historia, pues parte de procesos racionales reflexivos como la dialógica, el debate, el discurso, la narrativa y la retórica, elementos que son esenciales para la veracidad y el convencimiento de diversas posturas en defensa de una tesis o teoría (Risco del Valle, 2015). Por tanto, la argumentación hace parte de la formación académica y es un aspecto fundamental a desarrollar en el aula.

Según Weston (2005), el propósito de los procesos argumentativos es dar razones o pruebas que apoyen una conclusión desde diversos puntos de vista, usando una lógica formal o deductiva para estandarizar premisas y silogismos, y correlacionar causas y efectos, para evitar falsas interpretaciones. Así mismo, señala que el educando en su proceso de razonamiento debe partir de conceptos o códigos que generen una 
estructura coherente frente a su justificación y sus conclusiones, teniendo como recurso un discurso narrativo u oral que permita entrar en discusión para defender o refutar una idea.

Por su parte, Torres y Cristancho (2018) sugieren que la argumentación no es un proceso natural, sino que debe recurrir a escenarios y prácticas, señalando que incluir la argumentación en el aula como proceso pedagógico favorece una posición científica sólida, que aporta a la capacidad de debate de los estudiantes, al robustecer la estructura del argumento desde un proceso social dinámico, lo cual les permite producir planteamientos más eficaces usando como referencia datos, evidencias y pruebas. Esto a su vez, logra un mayor grado de persuasión. Por ello, la argumentación es una puerta para acceder al conocimiento, comprender la práctica científica y generar un pensamiento crítico, (Kuhn, 2010; Berland \& Lee, 2012).

La argumentación es una habilidad que se estructura en el aula de clase, a partir de dinámicas que permiten la confrontación y la refutación en defensa de una idea. Estudios recientes abordados por Torres y Cristancho(2019), señalan que esta habilidad se da en un contexto discursivo, donde se confrontan y defienden diversas perspectivas. También investigaciones de Toulmin (1985), Tamayo (2014), Pinochet (2015), González y Puig (2017), Jiménez y Puig (2010), vinculan los procesos de argumentación al fortalecimiento del pensamiento crítico, a partir del abordaje de Cuestiones Socio Científicas [CSC] para potenciar habilidades en la escuela. Los autores señalan las aportaciones reflexivas, discursivas y narrativas a los estudiantes, donde el argumento científico se perfila como estrategia para la solución de problemas del contexto social o local.

Es posible señalar que las CSC permiten al estudiante establecer relaciones entre los contenidos de las ciencias y el contexto, estructurar, diseńar, reflexionar, justificar y argumentar, con el objetivo de desarrollar habilidades propias del pensamiento crítico y científico (Torres \& Cristancho, 2018). Por ello, la argumentación en ecología resulta fundamental en la formación integral de los ciudadanos, especialmente en los entornos rurales que exigen toma de decisiones acerca del cuidado y manejo de los recursos del entorno.

Esta investigación toma como base los contenidos para la enseñanza de las ciencias naturales propuestos en los estándares del Ministerio de Educación Nacional [MEN] (2004), y los Derechos Básicos de Aprendizaje [DBA] (MEN, 2016) para la educación en Colombia. Contenidos mínimos que se pretenden abordar desde la perspectiva ecológica con estudiantes de básica secundaria, para evidenciar su relación con el contexto local, involucrando temas alusivos al páramo y al bosque andino, cadenas tróficas, calentamiento global, cambio climático, servicios ecosistémicos. Para ello, se acudirá al abordaje de CSC como estrategia para influir de forma determinante en el pensar y el actuar de los participantes y su entorno. 


\section{Metodología}

El estudio tomó como base una perspectiva cualitativa. Esta se caracteriza por depender de factores como las condiciones sociales o culturales, la población, el objeto de estudio, y las metas o particularidades del proyecto (Vasilachis, 2006). Así mismo, el estudio se enfoca bajo un paradigma hermenéutico interpretativo, (Barbera \& Inciarte, 2012). En este sentido, se asume el discurso de aula (Jiménez \& Díaz, 2003; Torres \& Cristancho, 2018) para la interpretación y posicionamiento de los estudiantes en relación a CSC sobre ecología.

\section{Participantes}

En la etapa diagnóstica participaron 11 estudiantes: siete de grado octavo y cuatro de grado noveno, con edades entre los 12 y 15 años, pertenecientes a una institución educativa pública del departamento de Boyacá que desarrolla el modelo escuela nueva. El colegio está ubicado en la zona andina de Colombia en el municipio de Chinavita. El muestreo fue no probabilístico intencional "la elección no depende de la probabilidad, sino de las razones relacionadas con sus características y contexto de la investigación" (Hernández- Sampieri \& Torres, 2018, p. 200). El estudio fue realizado en el mes de marzo de 2020 en medio de la emergencia sanitaria declarada por el gobierno nacional a causa de la pandemia ocasionada por el COVID-19.

\section{Momentos de Estudio}

Para el desarrollo de la fase diagnóstica se plantearon cuestionamientos relacionados con contenidos de las ciencias naturales, específicamente de ecología, que abordaron la temática bosque andino y páramo, propias del contexto local. Se estructuraron etapas, actividades y propósitos objeto de la aplicación del test, centrando el contenido a documentos y videos en el contexto de los estudiantes, con el fin de evidenciar las formas de argumentación y abordaje de los cuestionamientos (Tabla 1). Se usaron los criterios frente a las formas de argumentar como elemento de análisis, estrategia desarrollada por Torres y Cristancho (2018).

El trabajo de campo se desarrolló teniendo como base la participación, discusión y narrativa de los estudiantes al momento de brindar una respuesta a los cuestionamientos expuestos en el test.

Las preguntas del instrumento diagnóstico, así como las cinco seleccionadas para brindar una visión clara sobre las formas de argumentación y evaluación objetiva se centraron en los DBA, estándares básicos en ciencias naturales y criterios mínimos de valoración (Tabla 2 ). 
Tabla 1

Descripción e Intencionalidad de las Actividades Aplicadas en el Test.

\begin{tabular}{|c|c|c|}
\hline Etapa & Actividad & Desarrollo \\
\hline Introducción & $\begin{array}{l}\text { Intencionalidad } \\
\text { y orientación }\end{array}$ & $\begin{array}{l}\text { Se realiza una inducción a los estudiantes sobre el propósito de la } \\
\text { prueba, criterios y proceso de desarrollo de la misma. Se reciben los } \\
\text { consentimientos firmados de los estudiantes y padres de familia. }\end{array}$ \\
\hline \multirow{9}{*}{ Organización } & $\begin{array}{l}\text { Formación de } \\
\text { grupos }\end{array}$ & $\begin{array}{l}\text { Se procede a la organización de los estudiantes en dos grupos. Grupo } 1 \\
\text { (G1) y grupo } 2 \text { (G2). Mezclando los estudiantes de ambos grados, con el } \\
\text { objeto de observar y promover el discurso de aula. }\end{array}$ \\
\hline & $\begin{array}{l}\text { Asignación de } \\
\text { Roles }\end{array}$ & $\begin{array}{l}\text { Se realiza la distribución de roles en cada grupo, como: Relator, secretario, } \\
\text { receptor de materiales, vocales, controlador del tiempo. Quienes a su vez } \\
\text { asumieron las funciones establecidas en clase. }\end{array}$ \\
\hline & $\begin{array}{l}\text { Entrega del } \\
\text { material }\end{array}$ & $\begin{array}{l}\text { Entrega del test cuyo fin es conocer la postura argumentativa de los } \\
\text { estudiantes frente a } 13 \text { preguntas abiertas. El material se complementa } \\
\text { con dos lecturas, tres videos y dos imágenes como fuentes de inducción } \\
\text { y realimentación a conceptos para que el estudiante tenga herramientas } \\
\text { para el proceso de argumentación y ejecución del test. Los recursos } \\
\text { complementarios fueron: }\end{array}$ \\
\hline & & $\begin{array}{l}\text { Lectura 1. Páramo de Mamapacha. Texto enfocado en la caracterización e } \\
\text { importancia del páramo de Mamapacha como elemento fundamental del } \\
\text { contexto de los participantes. }\end{array}$ \\
\hline & & $\begin{array}{l}\text { Lectura 2. Servicios ecosistémicos [S.E.]. Artículo que aborda los S.E. de } \\
\text { relación. }\end{array}$ \\
\hline & & $\begin{array}{l}\text { Video 1. Bosque Andino [B.A.]. Aborda la distribución del Oso Andino o } \\
\text { de Anteojos en el macizo de Mamapacha - Bijagual, y la relación flora y } \\
\text { fauna del B.A. correspondiente al contexto en el cual circunda su diario } \\
\text { vivir el educando. }\end{array}$ \\
\hline & & $\begin{array}{l}\text { Video 2. Ecosistema [E]. Detalla qué es el ecosistema. Se realimentan } \\
\text { conceptos y códigos científicos. }\end{array}$ \\
\hline & & $\begin{array}{l}\text { Video 3. Transferencia de energía [T.E.]. Aborda el flujo de energía en el } \\
\text { ecosistema, la T.E. en un ecosistema, red trófica y cadenas alimenticias. }\end{array}$ \\
\hline & & $\begin{array}{l}\text { Imágenes } 1 \text { y 2. Factor antrópico [F.A.]. Presentan el antes, el ahora y el } \\
\text { después de un ecosistema. Las imágenes revelan el factor antrópico, en el } \\
\text { uso y abuso de los recursos eco-sistémicos sin una mirada de su contexto. }\end{array}$ \\
\hline \multirow{5}{*}{ Ejecución } & Aplicación & $\begin{array}{l}\text { Se estableció como tiempo de aplicación del test dos horas, divididas en } \\
\text { tres fases de } 40 \text { minutos. }\end{array}$ \\
\hline & $\begin{array}{l}\text { Fase } 1 . \\
\text { Preguntas } 1 \text { a } 4 .\end{array}$ & $\begin{array}{l}\text { En este apartado se compartió con los estudiantes una lectura } 1 \text { (páramo } \\
\text { de Mamapacha) y vídeo } 1 \text { (Bosque Andino), por tener relación con el } \\
\text { contexto local. Se propone a los estudiantes que refuten o justifiquen la } \\
\text { lectura con el fin de favorecer escenarios de discusión y se posibiliten } \\
\text { espacios de conexión hipotéticos con argumentos concretos. }\end{array}$ \\
\hline & $\begin{array}{l}\text { Fase } 2 . \\
\text { Preguntas } 5 \text { a } 8\end{array}$ & $\begin{array}{l}\text { Se presenta a los estudiantes la lectura } 2 \text { (Servicios Ecosistémicos). Se } \\
\text { busca que los estudiantes relacionen la importancia de los servicios para } \\
\text { el equilibrio ecosistémico, ecológico, y a su vez analicen de forma reflexiva } \\
\text { y dialógica sus cuestionamientos a partir de las lecturas } 2 \text { (Servicios } \\
\text { ecosistémicos) y los videos } 1 \text { (Bosque Andino), } 2 \text { (Ecosistema). }\end{array}$ \\
\hline & $\begin{array}{l}\text { Fase. } 3 . \\
\text { Preguntas } 9 \text { a } 13\end{array}$ & $\begin{array}{l}\text { Se analiza la capacidad de argumentación de los educandos y su } \\
\text { correlación con el material entregado. }\end{array}$ \\
\hline & & $\begin{array}{l}\text { Se presentan las dos imágenes de apoyo con el fin de establecer la relación } \\
\text { del ser humano como ente sistémico y ecológico con su contexto, y su } \\
\text { importancia en el equilibrio de los recursos ecosistémicos o ecológicos. }\end{array}$ \\
\hline
\end{tabular}

Nota: Elaboración propia. 
Tabla 2

Preguntas y criterios minimos de valoración para analizar las formas de argumentación.

\begin{tabular}{|c|c|c|c|}
\hline Pregunta & $\begin{array}{l}\text { Criterios mínimos para el aná- } \\
\text { lisis y valoración, contenido, } \\
\text { estructura y formas de discurso }\end{array}$ & $\begin{array}{l}\text { Derechos Bási- } \\
\text { cos de Aprendi- } \\
\text { zaje (DBA). }\end{array}$ & $\begin{array}{l}\text { Estándares Básicos en } \\
\text { ciencias Naturales. }\end{array}$ \\
\hline $\begin{array}{l}\text { 1. ¿Por qué la pérdida } \\
\text { o fragmentación de los } \\
\text { ecosistemas naturales } \\
\text { conllevan al peligro de } \\
\text { extinción de las espe- } \\
\text { cies? }\end{array}$ & $\begin{array}{l}\text { Valorar si los estudiantes utilizan } \\
\text { contenidos como: desequilibrio de } \\
\text { las cadenas tróficas; introducción } \\
\text { de especies no endémicas; dismi- } \\
\text { nución de las especies por caza } \\
\text { indiscriminada; deforestación de } \\
\text { flora nativa }\end{array}$ & \multirow{2}{*}{$\begin{array}{l}\text { "Comprende que } \\
\text { en las cadenas } \\
\text { y redes tróficas } \\
\text { existen flujos de } \\
\text { materia y energía, } \\
\text { y los relaciona } \\
\text { con procesos de } \\
\text { nutrición, foto- } \\
\text { síntesis y respi- } \\
\text { ración celular"(- } \\
\text { MEN, 2016, p. 25) }\end{array}$} & \multirow{3}{*}{$\begin{array}{l}\text { "Identifico condiciones } \\
\text { de cambio y de equili- } \\
\text { brio en los seres vivos y } \\
\text { en los ecosistemas" } \\
\text { Entorno vivo "Carac- } \\
\text { terizo ecosistemas y } \\
\text { analizo el equilibrio } \\
\text { dinámico entre sus po- } \\
\text { blaciones; Describo y } \\
\text { relaciono los ciclos del } \\
\text { agua, de algunos ele- } \\
\text { mentos y de la energía } \\
\text { en los ecosistemas" } \\
\text { Entorno físico. "Rela- } \\
\text { ciono energía y movi- } \\
\text { miento; Establezco re- } \\
\text { laciones entre energía } \\
\text { interna de un sistema } \\
\text { termodinámico, tra- } \\
\text { bajo y transferencia de } \\
\text { energía térmica" }\end{array}$} \\
\hline $\begin{array}{l}\text { 2. Explique la transfe- } \\
\text { rencia de energía del } \\
\text { medio natural al Oso } \\
\text { de Anteojos -tremarctos } \\
\text { ornatus-, y este a su vez } \\
\text { al medio natural. }\end{array}$ & $\begin{array}{l}\text { Relacionar y utilizar conceptos y } \\
\text { contenidos acerca de cadena tró- } \\
\text { fica, red alimenticia, aplicación de } \\
\text { la primera ley de la termodinámi- } \\
\text { ca, equilibrio eco-sistémico, dis- } \\
\text { persión de semillas y organismos } \\
\text { descomponedores. }\end{array}$ & & \\
\hline $\begin{array}{l}\text { 3. Los páramos y bos- } \\
\text { ques andinos son zonas } \\
\text { de protección debido a } \\
\text { la perdida de cobertura } \\
\text { forestal. ¿Qué acciones } \\
\text { o estrategias de protec- } \\
\text { ción de la biodiversidad } \\
\text { adelantaría en su con- } \\
\text { texto para evitar el de- } \\
\text { terioro de la cobertura } \\
\text { forestal? }\end{array}$ & $\begin{array}{l}\text { Involucrar contenidos como: polí- } \\
\text { ticas ambientales; cambio climáti- } \\
\text { co; calentamiento global; pérdida } \\
\text { de bosque nativo; campañas rela- } \\
\text { cionadas con el cuidado del medio } \\
\text { ambiente; reforestación; cuidado } \\
\text { de zonas de protección; evitar tala } \\
\text { de bosques y vegetación endémi- } \\
\text { ca; evitar la quema de cobertura } \\
\text { vegetal; uso indiscriminado de } \\
\text { agroquímicos (insecticidas, pla- } \\
\text { guicidas, fungicidas, entre otros) }\end{array}$ & & \\
\hline $\begin{array}{l}\text { 4. ¿Cuáles serían los } \\
\text { servicios eco sistémicos } \\
\text { más importantes en el } \\
\text { ecosistema de páramo } \\
\text { y bosque andino? Ex- } \\
\text { plique }\end{array}$ & $\begin{array}{l}\text { Contenido del argumento. Valorar } \\
\text { si los estudiantes identifican con- } \\
\text { tenidos propios del contexto local; } \\
\text { beneficio de los ecosistemas a las } \\
\text { comunidades; regulación y miti- } \\
\text { gación de fuentes hídricas; man- } \\
\text { tenimiento de la biodiversidad; } \\
\text { aportes del ecosistema a la vida } \\
\text { natural (el agua que nos brinda, la } \\
\text { alimentación, entre otros); aportes } \\
\text { culturales, de recreación, acadé- } \\
\text { micos o científicos. }\end{array}$ & & $\begin{array}{l}\text { Ciencia tecnología y } \\
\text { Sociedad. "Identifico } \\
\text { recursos renovables } \\
\text { y no renovables y los } \\
\text { peligros a los que es- } \\
\text { tán expuestos debido } \\
\text { al desarrollo de los } \\
\text { grupos humanos; jus- } \\
\text { tifico la importancia } \\
\text { del recurso hídrico en } \\
\text { el surgimiento y desa- }\end{array}$ \\
\hline $\begin{array}{l}\text { 5. ¿Por qué se dice que } \\
\text { la leyenda de Mama- } \\
\text { pacha prevalece como } \\
\text { símbolo ecológico? }\end{array}$ & $\begin{array}{l}\text { Contenido del argumento. Valorar } \\
\text { los saberes culturales de los estu- } \\
\text { diantes en relación al contexto lo- } \\
\text { cal: hace parte de la cultura local; } \\
\text { da identidad al contexto cultural } \\
\text { y social; por la riqueza natural en } \\
\text { flora y fauna; símbolo ecológico } \\
\text { para los habitantes de la región; } \\
\text { símbolo de abundancia del agua. }\end{array}$ & & $\begin{array}{l}\text { rrollo de comunidades } \\
\text { humanas; Identifico } \\
\text { factores de contamina- } \\
\text { ción en mi entorno y } \\
\text { sus implicaciones para } \\
\text { la salud"(MEN, 2004, } \\
\text { p. 18-19). }\end{array}$ \\
\hline
\end{tabular}

Nota: Elaboración propia con base en los postulados de Torres \& Cristancho (2018). 
Para la evaluación y análisis de las formas de argumentación se tomó la rúbrica propuesta por Torres y Cristancho (2018), la cual plantea tres niveles de argumentación, donde 3 representa el nivel máximo y 1 el nivel mínimo (Tabla 3). Además los criterios mínimos de valoración (Tabla 2) permitieron examinar conceptualmente la percepción de los estudiantes sobre las temáticas abordadas. Igualmente, desde una perspectiva narrativa se estudiaron las formas de argumentar teniendo en cuenta el contenido, estructura y discusión durante el desarrollo del test, lo cual permitió identificar elementos para comprender los planteamientos que tienen los estudiantes acerca del abordaje de temas en contexto.

\section{Tabla 3}

Rúbrica para el Análisis de las Formas de Argumentación de los Estudiantes

\begin{tabular}{|c|c|c|c|}
\hline $\begin{array}{l}\text { Aspectos } \\
\text { de análisis }\end{array}$ & Descripción & Nivel & Descripción de puntos \\
\hline \multirow{3}{*}{$\begin{array}{l}\text { Contenido del } \\
\text { argumento }\end{array}$} & \multirow{3}{*}{$\begin{array}{l}\text { El uso de datos, con- } \\
\text { ceptos, afirmaciones } \\
\text { o garantías, en los ar- } \\
\text { gumentos. } \\
\text { Valoración de la per- } \\
\text { tinencia de las refe- } \\
\text { rencias conceptuales }\end{array}$} & 3 & $\begin{array}{l}\text { - Afirmaciones soportadas en datos y conceptos cien- } \\
\text { tíficos explicativos y apoyados en fuentes de conoci- } \\
\text { mientos. }\end{array}$ \\
\hline & & 2 & $\begin{array}{l}\text { - Argumentos que contienen datos y conceptos pero } \\
\text { algunos de ellos son usados de manera incorrecta, o } \\
\text { imprecisa o incompleta. }\end{array}$ \\
\hline & & 1 & $\begin{array}{l}\text { - Argumentaciones que no presentan datos ni concep- } \\
\text { tos científicos explicativos. }\end{array}$ \\
\hline \multirow{3}{*}{$\begin{array}{l}\text { Estructura del } \\
\text { argumento }\end{array}$} & \multirow{3}{*}{$\begin{array}{l}\text { La complejidad de la } \\
\text { argumentación veri- } \\
\text { ficable en la acepta- } \\
\text { bilidad, la coherencia } \\
\text { y la suficiencia de los } \\
\text { argumentos. }\end{array}$} & 3 & $\begin{array}{l}\text { - Argumentos que son coherentes entre los datos, las } \\
\text { justificaciones y las conclusiones, esto es, la justifica- } \\
\text { ción es suficiente para validar lo que se quiere defen- } \\
\text { der. }\end{array}$ \\
\hline & & 2 & $\begin{array}{l}\text { - Argumentos que presentan coherencia pero que re- } \\
\text { quieren de mayor complejidad y relevancia }\end{array}$ \\
\hline & & 1 & $\begin{array}{l}\text { - Argumentos que no tienen coherencia ni suficiencia } \\
\text { con el establecimiento de conclusiones. }\end{array}$ \\
\hline \multirow[t]{3}{*}{$\begin{array}{l}\text { Formas de dis- } \\
\text { cusión }\end{array}$} & \multirow{3}{*}{$\begin{array}{l}\text { Contra argumenta- } \\
\text { ciones, refutaciones, } \\
\text { reafirmaciones o } \\
\text { aceptación frente a las } \\
\text { argumentaciones de } \\
\text { otros compañeros. }\end{array}$} & 3 & $\begin{array}{l}\text { - Frente a argumentos vacíos de contenido o incohe- } \\
\text { rentes propone posturas contrarias y las soporta con } \\
\text { conceptos, datos y fuentes de conocimientos } \\
\text { - Frente a argumentaciones coherentes pero incomple- } \\
\text { tas propone conceptos, datos y fuentes de conocimien- } \\
\text { tos que ahondan y perfeccionan la argumentación }\end{array}$ \\
\hline & & 2 & $\begin{array}{l}\text { - Frente a diversos argumentos propone posturas con- } \\
\text { trarias o complementarias, pero sin apoyarlas en fuen- } \\
\text { tes de conocimiento o con uso inexacto de conceptos. }\end{array}$ \\
\hline & & 1 & $\begin{array}{l}\text { - Acepta posturas sin cuestionamiento de ningún tipo } \\
\text { o sin complementar o dar razón de la argumentación. }\end{array}$ \\
\hline
\end{tabular}

Nota: Tomada de Torres y Cristancho (2018, p. 64).

\section{Resultados y Discusión}

A continuación se describe el análisis de cinco preguntas planteadas a los estudiantes. Las respuestas se abordaron teniendo en cuenta los criterios mínimos de valoración presentados en la tabla 2 y los tres niveles de análisis establecidos por 
Torres y Cristancho (2018) (tabla 3).

La primera pregunta del test, "¿Por qué la pérdida o fragmentación de los ecosistemas naturales conllevan al peligro de extinción de las especies?” genero las siguientes respuestas.

G.1. "Por las condiciones de alta humedad y ambiente en el que habitan, por la destrucción del ser humano hacia el ecosistema".

G.2. "Porque no sabemos cuidar nuestro ecosistema y no encuentran alimentación para sobrevivir".

En este sentido, las respuesta pretendía identificar la influencia de diferentes variables que ponen en riesgo las dinámicas del ecosistema, evidenciando la postura pre conceptual, conceptual estructural, a partir de la narrativa por parte de los participantes respecto a su propio contexto,

A lo anterior los estudiantes moldearon una perspectiva acorde a lo que experimentan en su medio, no obstante, no se visibiliza la relación con la información referenciada en el documento de apoyo, ni se genera reflexión o discusión en el grupo para organizar una respuesta contundente frente al uso de algunos códigos. Así mismo, en las soluciones no se encuentra justificación y conclusión sólida acorde al cuestionamiento, pues las respuestas son superficiales y con poca profundidad en el argumento. Al respecto, y de acuerdo con Jiménez y Puig (2010) lo que se busca con los procesos argumentativos es que los estudiantes logren relacionar efectos y causas frente a lo que experimentan, a partir de un fenómeno.

A partir de lo anterior, se determinó que no se develan argumentos en las respuestas de los estudiantes ya que no relacionan causas o efectos contemplados en los documentos entregados, ni se abordan los criterios mínimos contemplados (tabla 2). Ello implicó ubicar las repuestas en el nivel 1 acorde a las formas de argumentación presentadas en la tabla 3. Se destaca que los estudiantes se basan en sus preconceptos, experiencias cercanas sobre lo que escuchan, evidencian y viven en el entorno social de su contexto local.

La segunda pregunta del test aplicado, "Explique la transferencia de energía del medio natural al Oso de Anteojos tremarctos ornatus, y este a su vez al medio natural". Generó repuestas como:

G.1. "El medio natural le produce tanto alimento vegetal como carnívoro. Este se encuentra en el 4 nivel de la red trófica alimentaria y este te proporciona al medio dispersar las semillas como polinizar al transportar el polen en su pelaje".

G.2. "Del medio natural al oso la vegetación le aporta la alimentación y el hogar que necesita y el oso le aporta a la vegetación el abono y las semillas para que crezcan nuevas plantas". 
El propósito era generar la interacción de conceptos teóricos (Jiménez \&Puig, 2010).os criterios mínimos establecidos — flujo de energía y redes tróficasestuvieron correlacionados con el material complementario. Los estudiantes deben lograr redirigir la respuesta a las causas o consecuencias positivas que genera la transferencia de energía o primera ley de la termodinámica al entorno, para ello se busca que relacionen y estructuren una respuesta objetiva frente al cuestionamiento establecido.

Se encontró que las respuestas integran de manera clara conceptos y códigos científicos como red alimentaria, haciendo uso del material teórico presentado y como criterio mínimo de evaluación (Tabla 2), no obstante, algunos estudiantes usaron de forma incorrecta esta información, como se evidencia en la respuesta: "Como carnívoro este se encuentra en el 4 nivel de la red trófica alimentaría”. Al observar la justificación y la conclusión de la respuesta, se encuentra que brindan coherencia, pero se pierde relevancia y profundidad del tema, además, se observó la carencia de discusión frente al mismo cuestionamiento.

Es importante resaltar, que abordar problemas como el cuestionado en la pregunta (Sosa \& Dávila, 2019), relacionado con la transferencia de energía o tercera ley de la termodinámica, es algo complejo con relación a la dinámica de los ecosistemas en cuanto a flujo de energía se refiere y relación de organismos en la cadena trófica (González \& Puig, 2017). El análisis a través de los criterios establecidos, determinó que las respuestas presentadas en la segunda pregunta del test se ubican el nivel 2, para contenido y estructura, y en el nivel 1 con relación a las formas de discusión.

Al abordar la pregunta tres. "Los páramos y bosques andinos son zonas de protección debido a la perdida de cobertura forestal. ¿Qué acciones o estrategias de protección de la biodiversidad adelantaría en su contexto para evitar el deterioro de la cobertura forestal?" se evidenciaron las siguientes respuestas:

G.1. "Realiza campańas sobre el cuidado de la fauna y flora de los bosques nativos que nos proporcionan alimento y vida".

G.2. "Cuidando nuestro medio ambiente, como no talar los árboles, no combinando las fuentes hídricas y no cazando animales".

Por consiguiente es importante aclarar que el sentido de evaluación de la respuesta se centró en la comunicación. Jiménez y Díaz (2003) evocan a Vygotsky para abordar las situaciones donde la expresión dialógica y narrativa combinan lo social con lo cognitivo y se entiende el lenguaje como fuente de comunicación y estructuración de ciencias y aprendizaje. Así mismo, lo destacan como medio de correlación e integración de ideas previas con ideas conceptuales, lo que permite el análisis de la discusión en el aula a partir de la estructuración narrativa del discurso presente en las respuestas de los estudiantes.

Los datos obtenidos a partir de las respuestas narrativas y discusiones frente 
al cuestionamiento tres develan ideas previas soportadas por conceptos o códigos científicos, lo que acentúa lo expuesto por Jiménez y Díaz (2003),

El argumento de los estudiantes se basa en el discurso natural de ciencias naturales, donde además, los participantes retoman la experiencia propia de relación con el contexto, resaltando conceptos como "tala de bosque"; "No contaminación de fuentes hídricas"; "Cuidado de la flora y fauna"; "Bosques Nativos". Lo anterior da un argumento de contenido y estructura en las respuestas, pero se destaca la necesidad de profundizar en la justificación y conclusión (tabla 3), acudiendo a referentes a partir del material de apoyo suministrado en el desarrollo del test.

Sobre la pregunta cuatro, “¿Cuáles serían los servicios ecosistémicos más importantes en el ecosistema de páramo y bosque andino? Explique”, se presentaron las siguientes respuestas.

G.1. "Consideramos los servicios ecosistémicos de regulación. Los beneficios de regulación se obtienen directamente de los ecosistemas sin pasar por procesos de mercado que incluyen el aire limpio el mantenimiento de la capa de ozono son servicios relacionados con el control biológico y la regulación de enfermedades".

G.2. "Son los servicios de provisión llamados recursos naturales, el agua, los alimentos, madera y las fibras".

El cuestionamiento abordado tenía como objeto que los estudiantes lograran relacionar el concepto teórico bosque andino y páramo, referenciándolo con su contexto, pues el tema hace parte de su entorno cotidiano. Esto permite acercar la ciencia a la confrontación social de los estudiantes en relación al contexto del cual son promotores de conservación. Siguiendo los postulados de Bravo y Jiménez (2010), se destaca que la contextualización de conceptos aprendidos en el aula son importantes para la relación que establecen los estudiantes con el aprendizaje en su vida cotidiana.

$\mathrm{Al}$ respecto, conviene decir que la asimilación de conceptos relacionados con el contexto permite un proceso más reflexivo en los estudiantes, lo que promueve el identificar, razonar, justificar y argumentar, en las respuestas se pudo evidenciar la relación de códigos y referentes conceptuales científicos con coherencia, pero no se generó una justificación y conclusión relevantes frente al contexto, por ende el argumento no es profundo ni sólido, ubicando sus respuestas en los niveles de 2 de contenido y estructura, nivel 1 en las formas de discusiónabla 3). En este sentido, Bravo y Jiménez (2010) resaltan la necesidad que los estudiantes no solo mencionen conceptos, sino que desarrollen la capacidad de relacionar los aprendizajes adquiridos en el aula a la hora de justificar y concluir.

La pregunta cinco, "¿Por qué se dice que la leyenda de Mamapacha prevalece como símbolo ecológico?”. Develó las siguientes repuestas: 
G.1. "La leyenda de Mamapacha prevalece un símbolo ecológico ya que su esencia la ofrecían a la naturaleza en forma y conservación del agua alimentando lagunas y quebradas".

El cuestionamiento abordado, tuvo como propósito inducir al estudiante al reconocimiento ético y valorativo del entorno ecológico propio frente a la percepción social de la cultura ecológica global, como una corresponsabilidad para la preservación de los entornos ecosistémicos circundantes. En este sentido, Gonzáles y Puig (2017), y, Espańa y Prieto (2009), asumen la correlación evolutiva ser-biosfera como una meta de la educación y la sociedad, que además, involucra la responsabilidad de potenciar los valores ecológicos y éticos medioambientales.

En la pregunta cinco y acorde con las respuestas de los estudiantes, se puede aducir que asumen la leyenda y reserva natural Mamapacha como elemento de la cultura ecológica y de preservación en las dinámicas ecosistémicas de la región, lo que permite generar valores y emociones para la conservación y preservación de la flora, fauna y fuentes hídricas, al reconocerlas como elementos de vida propios del contexto inmediato.

No obstante, también se nota falta de profundidad en los referentes conceptuales usados, lo que le resta fuerza y solidez a la justificación y conclusión. Por lo anterior, se determina que las respuestas están en el nivel 2 de argumentación, referente a su contenido y estructura, y las formas de discusión se evalúan en el nivel 1 (tabla 3).

Al respecto conviene decir que los resultados del test diagnostico reflejan las correlaciones que hacen los estudiantes, a través de su narrativa sobre conceptos como bosque andino, páramo, servicios ecosistémicos, y flujo de energía, los cuales fueron abordados en lecturas y videos complementarios que se relacionaban con el entorno inmediato de los participantes. Por ello, se encontró una cercanía con el tema desde el conocimiento empírico sobre el bosque andino, pues, al ser el medio que habitan los educandos, establecieron relaciones desde el saber práctico de la flora y fauna del lugar.

También, se observó que la complejidad al momento de argumentar se generó en la organización de códigos científicos, la organización sistémica de los conceptos, la jerarquización de contenidos, y, la codificación y decodificación para enlazar la teoría con la práctica, lo que, sumado a la baja interpretación lectora se traduce en falta de correlación de códigos en el contenido y poca coherencia con la justificación. Lo anterior, conlleva errores en la estructuración del argumento, dificultades para profundizar el tema, referenciar, y asumir posiciones sólidas frente a la refutación o presentación de una tesis, por lo que se generan ideas carentes de lógica, coherencia y relación con lo que se cuestiona.

Así mismo, el diagnóstico permitió evidenciar el potencial de retomar la realidad de los estudiantes para favorecer un acercamiento exitoso a los conceptos científicos. 
En este sentido, plantear los cuestionamientos desde el contexto inmediato de los participantes facilitó que los estudiantes acudieran a sus experiencias y preconceptos para argumentar respuestas, lo que, finalmente es el objetivo final de las CSC. Pues estas favorecen una aproximación teórica y práctica más reflexiva, que repercute positivamente en la percepción y aplicación lógica de conceptos científicos en el contexto. Esto a su vez, implica para los estudiantes mayor apropiación de lenguaje y por ello, la estructuración del pensamiento científico, y, el desarrollo de habilidades y pensamiento argumentativo.

\section{Conclusiones}

El presente diagnóstico permitió identificar elementos para comprender las dificultades que deben asumir los estudiantes al momento de vincular correctamente información conceptual presentada como material de apoyo para el desarrollo de habilidades argumentativas. Se pretende entonces, fundamentar los conceptos científicos con una planeación estructurada acorde al contexto, metodologías y didácticas dinámicas, que comprometan e involucren a los estudiantes desde la solución de situaciones cotidianas propias de su entorno.

Por consiguiente, este estudio abre un proceso reflexivo frente al abordaje de conceptos, códigos y referentes científicos vistos en el aula; cómo presentarlos a los estudiantes de forma práctica y dinámica de manera que favorezca la enseńanza y aprendizaje de las ciencias, específicamente la ecología. Lo anterior, teniendo en cuenta la importancia de fortalecer las habilidades científicas, cognitivas, lingüísticas, y el pensamiento argumentativo de los estudiantes. Para ello, el proyecto al cual se adscribe este artículo desarrollará en etapas posteriores estrategias, prácticas pedagógicas y metodologías centradas en el discurso de aula, a partir de CSC para aportar al reconocimiento de los estudiantes como sujeto social en la estructuración del conocimiento científico.

El análisis presentado permite determinar que el abordaje de CSC a través de conceptos científicos y del entorno cotidiano de los estudiantes, favorece la asimilación, correlación y conceptualización acertada, en la estructuración de competencias científicas. En consecuencia, el aprendizaje puede ser más significativo y asertivo, una vez se proporcionen las herramientas adecuadas para la relación de conceptos, lo que, lleva a los estudiantes a reflexionar y actuar positivamente con su entorno.

Por último, el uso de los criterios de análisis de las formas de argumentación propuestos por Torres y Cristancho (2018), permitió desarrollar un proceso riguroso de evaluación frente a las argumentaciones de los estudiantes. Se destaca la precisión de los descriptores en cada nivel, pues esto ayuda significativamente para ubicar la respuesta de los estudiantes y determinar de acuerdo a las tres categorías de análisis -contenido, estructura y discurso- el cómo argumentan los participantes. Gracias 
a esto, la investigación tuvo un punto de partida claro y objetivo para el diseño de estrategias que se desarrollará en etapas posteriores de la investigación en curso.

\section{Referencias}

Barbera, N., \& Inciarte, A. (2012). Fenomenología y hermenéutica: dos perspectivas para estudiar las ciencias sociales y humanas. Multiciencias, 12(2), 199-205. https://www.redalyc.org/pdf/904/90424216010.pdf

Berland, L., \& Lee, V. (2012). In pursuit of consensus: Disagreement and legitimization during small-group argumentation. International Journal of Science Education, 34(12), 1857-1882. https://digitalcommons.usu.edu/cgi/viewcontent. cgi? article $=1261 \&$ context $=$ itls_facpub

Bravo, B., \& Jiménez Aleixandre, P. (2010). ¿¿Salmones o sardinas? Una unidad para favorecer el uso de pruebas y la argumentación en ecología. Alambique, Revista de didáctica de las ciencias experimentales, 15(63), 19-25. https://www.researchgate.net/profile/Beatriz-Bravo-3/publication/284609500_Salmones_o_sardinas_ Una_unidad_para_favorecer_el_uso_de_pruebas_y_la_argumentacion_en

España, E., y Prieto, T. (2009). Educar para la sostenibilidad: El contexto de problemas socio científicos. Eureka. 6(3), 345-354.

González, A., \& Puig, B. (2017). Analizar una problemática ambiental local para practicar la argumentación en clase de ciencias. Enseñanza de las Ciencias, 16(2), 280-297. http://reec.uvigo.es/volumenes/volumen16/REEC_16_2_6_ex1139. pdf

Hernández-Sampieri, R., \& Torres, C. (2018). Metodología de la investigación (Vol. 4). McGraw-Hill Interamericana.

Jiménez, M., \& Díaz, J. (2003). Discurso del Aula y Argumentación En La Clase de Ciencias: Cuestiones Teóricas y Metodológicas. Enseñanza de las ciencias, 21(3), 359-370. https://ddd.uab.cat/pub/edlc/02124521v21n3/02124521v21n3p359. pdf

Jiménez, M. \& Puig, B. (2010). Argumentación y evaluación de explicaciones causales en ciencias: el caso de la inteligencia. Alambique, Revista de didáctica de las ciencias experimentales, 63, 11- 18.

Kuhn, D. (2010). Teaching and learning science as argument. Science Education, 94(5), 810-824.

Ministerio de Educación Nacional. (2004). Estándares básicos en competencias en ciencias sociales y ciencias naturales. MEN. https://www.mineducacion.gov.co/1759/ article81033_archivo_pdf.pdf

Ministerio de Educación Nacional. (2016). Derechos Básicos de Aprendizaje de las 
Ciencias Naturales. https://aprende.colombiaaprende.edu.co/sites/default/files/ naspublic/DBA_C.Naturales.pdf

Ministerio de Educación Nacional. (2018). Día e. Guía de interpretación del ISCE del cuatrienio. Uso de resultados hacia el mejoramiento continúo.

Pinochet, J. (2015). El modelo argumentativo de Toulmin y la educación en ciencias: una revisión argumentada. Ciência \& Educação, 21(2), 307-327. https://doi. org/10.1590/1516-731320150020004

Risco del Valle, E. (2015). Las teorías de la argumentación en el tiempo I: La época fundacional. Alpha, 40, 81-93. http://dx.doi.org/10.4067/S071822012015000100007

Sosa, J. A., \& Dávila, D. T. (2019). La enseñanza por indagación en el desarrollo de habilidades científicas. Educación Y Ciencia, (23), 605-624. https://doi. org/10.19053/0120-7105.eyc.2019.23.e10275

Tamayo, Ó. E. (2014). Pensamiento crítico dominio-específico en la didáctica de las ciencias. Tecné, Episteme y Didaxis: TED, 36, 25-45. https://doi. org/10.17227/01203916.4686

Toulmin, S. (1958). The uses of argument. Cambridge University Press.

Torres, N., \& Cristancho, J. (2019). Promoviendo y conceptualizando la argumentación en la formación docente. Enseñanza y Aprendizaje de las Ciencias en Debate, (2), 448-456.

Torres, N., \& Cristancho, J. (2018). Analysis of theforms of argumentation of teachers in training in the context of asocio-scientific issue. Journal of Turkish Science Education, 11(1),3-23. https://tused.org/index.php/tused/article/view/149

Vasilachis de Gialdino, I. (2006). Estrategias de la investigación cualitativa. Gedisa.

Weston, A. (2005). Las Claves de la Argumentación. Ariel 